\title{
Possibilidades e entraves de uma comunidade virtual de prática nas aulas de matemática na educação de jovens e adultos
}

\author{
Eduardo Brito Correia ${ }^{1}$
}

\section{Resumo}

Este trabalho busca relatar o estudo empírico, desenvolvido em uma escola pública do município de Feira de Santana e se constitui no resultado da minha pesquisa no programa de Mestrado Profissional em Educação de Jovens e Adultos (MPEJA) na UNEB, que teve como objetivo identificar entraves e possibilidades, a partir do uso de um aplicativo de smartphones, para delinear uma comunidade virtual de prática, nas aulas de Matemática, na Educação de Jovens e Adultos (EJA). Para tanto, foi utilizado, como interface comunicacional, o aplicativo WhatsApp mediado por estratégias pedagógicas, as quais possibilitaram aos sujeitos envolvidos, um espaço de socialização e aprendizado na disciplina Matemática. Pensando na necessidade de dar visibilidade às vozes dos interlocutores do processo formativo, através da pesquisa-ação, partiu-se do seguinte questionamento: "Aplicativos de troca de mensagens utilizados em dispositivos móveis podem favorecer a instituição de comunidades virtuais de prática nas aulas de Matemática na EJA?" Nesta perspectiva, foi estabelecido um diálogo com os autores que abordam as categorias de análise da temática em questão, entre eles, Freire (1987), Wenger (1998), Costa (2007), Silva (2008), Thiollent (2009) e outros. A partir da análise dos elementos observados no processo, foi possível evidenciar as aprendizagens realizadas e algumas perspectivas possíveis, tais como, a ampliação dos espaços de construção do universo cognitivo, referenciando novas e/ou diferentes possibilidades de aprofundamento/consolidação das estruturas que estão contidas no universo da Matemática e o fortalecimento da proposta de emancipação do sujeito, no que tange a realçar o papel central do aluno no processo ensino-aprendizagem.

Palavras-chave: educação de jovens e adultos; educação matemática; comunidade virtual de prática

Recepción: 26/04/2021

Evaluación 1: 11/05/2021

Evaluación 2: 13/05/2021

Aceptación: 19/05/2021

\section{Introdução}

A utilização das TICs - Tecnologias da Informação e Comunicação na escola, algumas vezes, é negligenciada pelos docentes, uns por desconhecerem essa ferramenta como colaboradora para o ensino e outros por considerarem desnecessário o uso de tecnologias na escola. Outro grupo de docentes e escolas até reconhecem a importância das TICs no âmbito escolar, contudo, não possuem acesso a esses instrumentos e nem a formação necessária para a sua utilização.

Sabemos que os sujeitos da EJA, assim como os demais, têm saberes que o professor deve respeitar, pois são saberes construídos no percurso de suas histórias de vida. Como afirma Fonseca (2005), os educadores precisam voltar a atenção para a compressão do sentido da experiência social e pessoal vivenciada por sujeitos marcados pela exclusão escolar. Tais sujeitos, quando jovens ou adultos, inserem-se num contexto de ensino e aprendizagem de resistência em todos os sentidos, especialmente a resistência à Matemática. 
A partir destas constatações é possível compreender que devemos suscitar questionamentos, compartilhar reflexões e apontar possibilidades de caminhos para um melhor e mais eficaz aprendizado de Matemática, na EJA. Deste modo, o ensino da Educação Matemática para Jovens e Adultos não pode representar apenas o ensino do conteúdo de uma disciplina, mas, assim como considera Fonseca (2005, p.45), deve representar uma "[...] ação educativa dirigida a um sujeito de escolarização básica incompleta ou jamais iniciada e que acorre aos bancos escolares na idade adulta ou na juventude".

Nesta direção, propus, ações que dialogassem, de forma implicada, com as categorias Educação Matemática, Comunidade de Prática, Educação de Jovens e Adultos (EJA) e o Uso de aplicativos em dispositivos móveis. Tal junção foi proposta a fim de que pudesse ampliar as possibilidades de aquisição e manutenção do conhecimento matemático dos sujeitos inseridos no contexto da Educação de Jovens e Adultos, de uma escola pública localizada na cidade de Feira de Santana/BA.

Desta forma, se constituiu como objetivo, no delineamento desta pesquisa empírica, a proposta de identificar entraves e possibilidades a partir do uso de aplicativos smartphones para delinear uma Comunidade Virtual de Prática (CdP), nas aulas de Matemática, na Educação de Jovens e Adultos (EJA). Tudo isso a partir da criação de um grupo de discussão virtual por meio do aplicativo Whatsapp para desenvolver atividades relativas às aulas de Matemática com uma turma de EJA, como forma de intervenção.

Imbuídos deste propósito, buscamos articular ações que trouxeram à baila alguns elementos circundantes desta pesquisa, especialmente a necessidade de nos aproximarmos dos constructos teóricos que lastreiam os estudos sobre Comunidades Virtuais de Prática (CdP), termo cunhado e definido por dois pesquisadores, Étienne Wenger e Jean Lave. Tais teóricos no início dos anos 90, apresentaram um modelo de aprendizagem cujo rearranjo propunha um engajamento em comunidade de prática em favor das estratégias de negócio.

O conceito de CdP proposto por estes teóricos nos diz que as comunidades de prática são formadas por grupos de pessoas que compartilham interesses, conjuntos de problemas ou uma paixão por um tópico e que aprofunde o seu conhecimento, expertise, na área, pela interação regular. Neste sentido, o aprendizado ganha contornos sociais, já que as experiências cognitivas, compartilhadas, vão além dos processos rotineiros e alargam-se nas práticas sociais desenvolvidas pelo grupo.

Nessa perspectiva, Rodríguez Illera, ao discutir sobre o significado do termo comunidade, confronta e apresenta diversas considerações e definições sobre o mesmo, demonstrando que:

Comunidade é uma palavra que provém do latim commune e communis, conjuntamente, em comum, conjunto de pessoas que se vinculam pelo cumprimento de obrigações comuns e reciprocas (Corominas, 1987) e que se utiliza desde meados do século XV. Além da sua raiz e acepção em usos importantes como comunismo e comunicação, o seu interesse teórico, pelo menos para os nossos propósitos (para uma revisão histórico-filosófica, ver Todorov, 1996), provém da distinção clássica de Tonnies (1979 [1887]) entre Comunidade e Associação. Tonnies elabora esta distinção no contexto de pensar formas distintas de agrupamento, particularmente as que distinguiriam a sociedade pré-industrial da que se desenvolve a partir do século XVIII e do século XIX, em especial. A Comunidade seria uma forma de agrupamento baseada na proximidade, partilha de experiências e formas de vida ou mundividências, sensibilidades e experiência, instituições como a família, mais ligada a ambientes rurais ou grupos de pequena dimensão; pelo contrário, a Associação reger-se-ia por um distanciamento experiencial e físico, um tipo de agrupamento baseado na conveniência, com uma duração temporal mais circunscrita aos interesses compartilhados. (RODRIGUEZ ILLERA, 2007, p.117) 
Também, para ampliar e dimensionar outro aspecto desta proposta de estudo recorremos a Pierre Levy, que nos adverte sobre os significados implícitos no termo virtual. Sobre o mesmo, tal autor assevera que:

\begin{abstract}
A palavra virtual vem do latim medieval virtualis, derivado por sua vez de virtus, força, potência. Na filosofia escolástica, é virtual o que existe em potência e não em ato. 0 virtual tende a atualizar-se, sem ter passado no entanto à concretização efetiva ou formal. A árvore está virtualmente presente na semente. Em termos rigorosamente filosóficos, o virtual não se opõe ao real mas ao atual: virtualidade e atualidade são apenas duas maneiras de ser diferentes. (LÉVY, 1996, p. 15)
\end{abstract}

Sob estes pontos de vista, expressos no pensamento dos dois autores, re-direcionamos o nosso olhar para os significados que redefinem uma comunidade no contexto virtual. Sendo assim, uma de suas bases deve ser, além da partilha, a compreensão de que seus membros devem assumir o papel de sujeitos que contribuem para a base do conhecimento em ascensão e não apenas meros receptores de seus serviços, compreendendo o meio no qual a informação circula como um motor que possibilita novas contingências.

Propostas tais considerações, cabe-nos assinalar as características de uma CdP, pelo olhar de Wenger (1998), destacando três elementos: Domínio, Comunidade e Prática compartilhada. O primeiro elemento é o domínio de interesse compartilhado, que tem como base a afirmação de seu propósito e valores comuns aos membros desta comunidade. 0 domínio ajuda a definir a identidade dos membros e define também competências que os distinguem de outras pessoas. No segundo elemento, temos a comunidade, ou seja, os membros e os seus respectivos relacionamentos. Ao buscar seus interesses, os membros desenvolvem atividades e discussões em conjunto, eles estabelecem relacionamento que permitem aprender uns com os outros, as interações entre os membros são essenciais para torná-los uma comunidade.

0 terceiro elemento é a prática compartilhada pela comunidade. A prática é representada através de um conjunto de esquemas de trabalho, de ideias, informações, instintos, linguagens, histórias e documentos que são compartilhados pelos membros da comunidade, o que podemos chamar de relato de experiência. A prática é o conhecimento específico que a comunidade desenvolve, partilha e mantém.

Considerando o cenário teórico descrito, ousamos dizer que foi determinante e primordial, na escolha do modelo de ambiente a que se propôs este estudo, a aproximação das concepções de Wenger com as de Paulo Freire. Ao construir a estrutura do que chama de Comunidade de Prática (CdP), como ambiente de aprendizagem, Wenger (1998) parte de premissas que possuem muitos pontos de contato com as de Freire ao explicitar a educação dialógica e problematizadora. As CdP's virtuais são os espaços presenciais que Freire usava nas capelas ou sindicatos ou até mesmo debaixo da mangueira, pois, aqui, não nos referimos apenas a um espaço físico, e sim o que o ambiente proporciona e estimula.

Foi nesta perspectiva que esta pesquisa buscou apresentar algumas contribuições no campo da educação, uma vez que procurou levar para o centro das discussões o uso dos dispositivos móveis numa vivência de uma comunidade de prática no contexto da Educação de Jovens e Adultos (EJA), na disciplina Matemática. Desta forma, foi possível verificar, também, as implicações oriundas da intervenção das Tecnologias da Informação e Comunicação no espaço de uma escola pública estadual, no município de Feira de Santana na Bahia.

\title{
Espaços e sujeitos: conexões acerca do caminho experienciado
}

A delimitação do campo empírico desta pesquisa foi determinada através do critério de atuação profissional do pesquisador. Desta forma, a Unidade de Ensino na qual foram 
desenvolvidas as intervenções relacionadas a esta proposta se constituíram em uma escola classificada, de acordo com normas específicas da Rede Estadual de Ensino da Bahia, como porte especial (21 salas, salas de multiuso, um laboratório de informática e outro de ciência, além de biblioteca, auditório e uma quadra poliesportiva), com mais de 1600 alunos matriculados.

A unidade escolar, mencionada acima, foi o Colégio Estadual Governador Luiz Viana Filho que fica localizado no município de Feira de Santana-Ba, no bairro da Cidade Nova. Nesta unidade, desenvolvemos a função de docente, desde 2005. De 2010 a 2015, atuamos em turmas da EJA, no tempo formativo III, na disciplina Matemática. Nos últimos anos exercemos a função de gestor da escola. É importante frisar que esta trajetória corroborou com a nossa aproximação com o Programa de Pós-Graduação - Mestrado Profissional em Educação de Jovens e Adultos (MPEJA).

A referida escola funciona nos três turnos, sendo que no matutino e no vespertino são ministradas aulas do Ensino Fundamental II e Ensino Médio regular, destacando no turno vespertino turmas do Tempo Juvenil, uma modalidade de ensino que a Secretaria de Educação do Estado da Bahia oferta para os jovens de 15 a 17 anos e ainda encontra-se no Ensino Fundamental II. No noturno, oferta-se turmas de EJA (Educação de Jovens e Adultos), assim como também as turmas de Tempo Juvenil e turmas do Ensino Médio.

A unidade escolar recebe, nos três turnos, estudantes do bairro e adjacências, além de estudantes moradores da zona rural dos diversos distritos que circundam a região. Um destaque a ser feito no que tange à matrícula dos alunos, no noturno, no ano letivo de 2018, deveu-se ao fato de a escola ter mais de 430 estudantes matriculados, sendo 340 na modalidade EJA.

Diante deste número expressivo de sujeitos matriculados, no noturno, e para melhor desenvolvimento da pesquisa, tornou-se necessária a escolha de uma turma. Assim, procuramos eleger uma turma que atendesse a alguns requisitos específicos e que pudesse dar uma melhor expressividade aos dados coletados e analisados durante o processo empreendido neste estudo. Assim, as aulas de matemática realizadas na turma de Exatas - EIXO VII - turma B, representou o recorte feito. A classe era composta por 27 estudantes. É importante assinalar que tal recorte foi alicerçado em duas premissas básicas:

1. Aceitação e acolhimento positivo da docente que ministrava aulas de matemática na referida classe;

2. Existência de um grupo de discussão virtual ancorado no aplicativo Whatsapp. 0 grupo foi criado anteriormente pelos próprios estudantes, objetivando uma comunicação instantânea que os auxiliasse acerca de informações de determinados assuntos relacionas ao contexto escolar e outras demandas, a exemplo de ausências nas aulas.

Diante dessa realidade, e após ter recebido autorização por parte da professora regente da disciplina Matemática, realizamos um primeiro contato com os alunos matriculados na referida classe para explicar a proposta de pesquisa e convidá-los a participar como sujeitos pesquisados. Nesta oportunidade foi deixada, para cada aluno, uma ficha de inscrição e autorização, além do roteiro da entrevista semiestruturada com perguntas pertinentes a determinados contextos em que os sujeitos pesquisados estavam imersos. Neste momento, 17 estudantes estavam presentes, assim sendo, objetivando acessar o maior número possível de alunos, a professora regente ficou com alguns roteiros da entrevista para entregá-los, posteriormente, aos estudantes ausentes. Um outro procedimento adotado foi o de 
disponibilizar o nosso número de contato telefônico, dando como opção gravar no Whatsapp as respostas da entrevista.

Constatamos, nesta visita, que o percentual de alunos que se constituíam membros do grupo já existente no Whatsapp era de, aproximadamente, $45 \%$ do número de alunos matriculados na turma. Tal informação evidenciou, ainda que de maneira subjetiva e despretensiosa, uma reflexão sobre o porquê desta discrepância entre o número total de alunos frequentes e a inclusão destes num grupo virtual, cuja característica proeminente era sua gênese (criado a partir das demandas de seus membros). Os outros 55\% informaram, quando questionados, dois motivos: falta de interesse em participar de grupos de Whatsapp e não possuir aparelho celular tipo smartphone.

A partir da realização da entrevista, momento em que estávamos na fase exploratória (Thiollent, 2011), conhecendo o grupo e explorando uma realidade com vistas a identificar características e expectativas deste, nos foi possível (re)conhecer elementos constituintes do perfil dos sujeitos. Esta etapa favoreceu de maneira positiva no reequacionamento das trajetórias traçadas ainda durante o projeto deste estudo, a medida que norteou 0 delineamento dos próximos passos a serem focalizados durante o processo de investigação.

Neste contato com o grupo, fomos descobrindo certas características que nos auxiliaram no redimensionamento da proposta. Uma destas descobertas foi a alta rotatividade no que tange à frequência entre seus estudantes: a frequência semanal do grupo situava-se em torno de $60 \%$ de alunos presentes, ou seja, a turma, em nenhum momento, tinha a sua presença na totalidade. Este percentual, porém, não se constituía diariamente pelos mesmos estudantes presentes regularmente nas aulas da turma, apenas $10 \%$ dos estudantes frequentavam as aulas todas as noites, no entanto, os demais tinham uma frequência esporádica.

Diante desse contexto, percebemos que o envolvimento do grupo na proposta estaria, de certa forma, fragilizado, já que não poderíamos contar com um grupo coeso e frequente, ao menos de forma presencial. Assim, decidimos solicitar aos estudantes a inclusão de nosso contato no grupo virtual da turma. Ao invés de criar um grupo novo, poderíamos buscar desenvolver o nosso estudo dentro de um espaço já existente de comunicação da turma, buscando alinhar o nosso interesse, para fins de pesquisa, aos do grupo sem, com isso, "invadir" este espaço de interações e trocas.

Nossa solicitação foi aceita e ao adentrarmos no ambiente do grupo de Whatsapp notamos, a princípio, o silêncio e a observação, sem interação por parte de aproximadamente $90 \%$ dos estudantes. Talvez, impelidos por um sentimento de vergonha ou por um certo grau de constrangimento, já que agora estávamos lá atuando como educadores num meio virtual, ainda que aquele espaço pudesse possibilitar uma forma diferente de acessar os conteúdos matemáticos estudados nas aulas presenciais. Através daquele grupo, os estudantes já compartilhavam imagens com os conteúdos ministrados pela professora da turma disponibilizada por um de seus membros e que registra um exercício sobre o assunto, gráficos de funções do $1^{\circ}$ grau, que foi estudado numa das aulas de matemática.

A partir dos dados coletados na entrevista, identificamos uma informação a ser considerada em sua relevância, no que diz respeito ao uso de recursos tecnológicos, especialmente do smartphone, como suporte de apoio às atividades extraescolares. Do universo de 14 alunos participantes, 13 alunos declararam fazer uso deste suporte para este fim e apenas uma das alunas estava fora deste ambiente pelo motivo de estar, no momento, fora do mercado de trabalho e sem condições financeiras de obter um aparelho (Smartphone), no qual o aplicativo Whatsapp e/ou outros, com a mesma finalidade, pudessem ser instalados. 
Quando questionados se participavam de grupos neste App e qual a finalidade dos mesmos, doze sujeitos responderam positivamente, sinalizando que a temática dos grupos, em sua maioria, era formada por pessoas amigas, membros da família e do trabalho. Neste universo, dois alunos negaram sua participação pelos seguintes motivos: o primeiro relatou que, no momento estava fora do mercado de trabalho e por essa questão não possuía um Smartphone e o segundo comentou não gostar deste tipo de comunicação virtual, ainda que possuísse um aparelho propício a este uso, bem como uma conta no aplicativo mencionado.

Ainda neste sentido, foi solicitado que os alunos entrevistados sugerissem alguma temática que pudesse ser analisada e discutida à luz de conceitos e estratégias circunscritas ao universo da Matemática, através do uso do aplicativo. Neste quesito, dos 14 entrevistados, apenas uma estudante que, nesse estudo será identificada pelo nome de Jaci, opinou, indicando-nos o tema: "Empoderamento da mulher no mercado de trabalho".

Diante desta solicitação advinda de um interesse concreto da educanda, demos início às discussões e estudos a que se propõe esta pesquisa com a primeira atividade proposta seguindo o tema sugerido pela referida estudante Jaci. Então, apresentamos a proposta da atividade no ambiente virtual do grupo no Wathsapp, que apresentam imagens das telas com o diálogo inicial de aproximação entre o estudo da Matemática e o uso do Wathsapp com vistas a perceber conexões possíveis na constituição de uma Comunidade de prática (CdP).

O grupo de discussão no Whatsapp era composto pelos seguintes sujeitos: o pesquisador, sua orientadora, o professor de matemática da turma e os estudantes, totalizando 21 membros, o que significa que entre os 18 estudantes presentes, 04 não quiseram participar da pesquisa.

Nesta direção e partindo do perfil da turma delineado pelas entrevistas, foram propostos no ambiente virtual, elementos para reflexões, problemas para serem solucionados coletivamente e formalização de conteúdos matemáticos, construídos com o professor da turma e os próprios estudantes. Isto por que, a metodologia escolhida nos direcionava à escuta dos sujeitos, corroborando com a proposta evidenciada na metodologia pesquisa-ação que assinala que "[...] um meio de resolução de problemas coletivos e como forma de aprendizagem dos atores e dos pesquisadores." (Thiollent, 2011, p.10)

Lançados os desafios, portanto, percebemos que o envolvimento no grupo contou com a participação efetiva de dois estudantes, ambos adultos acima de 35 anos. Destes, a estudante Jaci de 56 anos, que havia sugerido o tema, atuou de forma bastante participativa, inclusive de forma presencial, buscando motivar e explicar aos colegas como desenvolver tal atividade, conforme relato da professora regente.

Neste sentido, observamos que

A oferta de ambientes de aprendizagem confiáveis e a oportunidade de por em contacto pessoas com interesses comuns, colocar desafios e com motivações similares podem ser um dos atractivos destas comunidades, que valorizam a participação e iniciativa. 0 importante nas Comunidades de Prática são os conteúdos, ou seja, as aprendizagens como experiência através dos processos de negociação e re-negociação e de significação e re-significação e as modificações das competências, habilidades/aptidões e saberes individuais que podem interferir no exercício de pertença do indivíduo na comunidade. (SILVA, 2008, p.9)

Isso posto e, considerando o envolvimento do grupo na atividade foi-se delineando os contornos e estruturas de uma Comunidade de prática, na qual o propósito colaborativo fundamentou um processo aprendizagem situado na relação muitos para muitos, em oposição aos métodos de ensino tradicionais centrados na figura do professor como o único detentor do conhecimento. 
Assim, objetivando facilitar a resolução dos problemas propostos nas atividades fizemos um vídeo tutorial de aproximadamente cinco minutos, explicando sobre a definição de valor absoluto e valor relativo e como encontrá-los num rol de dados numéricos. Percebemos que este vídeo foi um dos instrumentos que auxiliou a estudante na orientação aos colegas. Após este investimento da estudante Jaci, o número de participantes na resolução do problema aumentou para 06 participações.

Aos desafios propostos que agregavam outros conhecimentos de base tecnológica, os estudantes, bem como as outras categorias participantes da pesquisa (professora de matemática, pesquisador e orientadora do estudo) foram tendo acesso, não apenas aos conceitos matemáticos inicialmente propostos. A estes, foram agregando-se novas ferramentas de base tecnológica no qual o currículo foi-se construindo com fluxos de uma coletividade.

\section{Algumas conclusões}

É irreversível a trilha entre a sociedade e a tecnologia e não há como fugir desta realidade. Por esta razão, faz-se necessário que a escola, juntamente com os seus pares reflitam sobre os novos vieses que o avanço da tecnologia vem trazendo à vida do homem. Sendo importante sobre a clareza da utilização desta dentro de um contexto escolar, pois se for utilizada dentro de um objetivo pedagógico, pode vir a agregar conhecimentos tanto aos educadores, quanto aos educandos.

Nesta perspectiva, é possível conceber este momento como "a era da informação", caracterizada pela convergência tecnológica e por uma informatização total das sociedades contemporâneas (Castells, 1996). Essa sociedade, passa hoje por uma nova fase, a dos computadores coletivos móveis, que chamaremos aqui de "era da conexão" (WEINBERGER, 2003), caracterizando-se pela emergência da computação ubíqua, ou seja, que está presente em todos os lugares ao mesmo tempo, e também uma computação pervasiva que se espalha e se infiltra por toda parte propagando-se nos diversos usos cotidianos. Este marco se dá com o surgimento dos celulares móveis com acesso à internet.

Cabe a nós, educadores, aproveitarmos deste cenário e utilizarmos estas ferramentas em proveito da produção de conhecimento na escola, tornando assim significativo o ambiente educacional e todo processo ensino-aprendizagem. Isto por que, os conteúdos de sala de aula fazem parte de um projeto social, é dever, deste projeto, integrar todas as ferramentas sociais à aprendizagem.

Torna-se necessário sinalizar alguns pontos que perpassam o uso de tais tecnologias na escola e a importância de uma educação que garanta o empoderamento do educando de forma significativa no uso dos dispositivos móveis. Entendemos que há limitação no uso de tais dispositivos, seja referente a formação do professor no manuseio destas ferramentas, como na formação docente centrada no sujeito e na escola, o que impacta a construção pedagógica. Contudo, se devem empreender esforços para compreender como transformar tais limitações em oportunidades para o desenvolvimento de novos dispositivos ou adaptações dos atuais, incluindo, definitivamente, as tecnologias móveis no processo de ensino-aprendizagem.

Assim, evidenciamos a primeira possibilidade de utilização deste aplicativo no contexto da EJA: não fomos nós, enquanto pesquisadores que provocamos a criação de um grupo virtual que servisse de meio para a comunicação da turma; ele já existia e se configurava como lócus de trocas entre os sujeitos. Nesse sentido não estava em nosso poder criar ou gerenciar este espaço, bastava-nos, portanto, ser integrados e quem sabe, de acordo com o desejo da maioria, redimensioná-lo, trazendo novos sentidos a fim de agregá-los aos já existentes. 
Para finalizar, acho importante ressaltar que esta experiência construiu-se em torno de aspectos como o medo, a ousadia, os dilemas, o desejo de ir além para trazer mais perto das instâncias acadêmicas uma reflexão que possa contribuir, significativamente, para o desvelamento de propostas que venham colaborar na efetivação de práticas e atitudes no contexto da EJA, que sejam uma resposta contrária ao status quo, no qual, o estudante desta modalidade é, na maior parte das vezes, tratado como objeto que não produz conhecimento e, portanto, está segregado a um contexto opressor e desvinculado de sua realidade.

\section{Referências}

Castells, M. (1996) The Rise of the Network Society. Volume I. The Information Age: Economy, society and culture. Oxford, Blackwell Publishers, 1996.

Costa C. (2007). 0 Currículo numa comunidade de prática. Sísifo. Revista de Ciências da Educação, 3, pp. 87-100. sisifo.fpce.ul.pt/? $r=11 \& p=87$

Freire, P. (1987) Pedagogia do oprimido. 17. ed. São Paulo: Paz e Terra.

Fonseca, M. C. F. R. (2005) Educação matemática de jovens e adultos: especificidades, desafios e contribuições. 1. ed. Belo Horizonte: Autêntica.

Lévy, P. (1996) O Que é o Virtual? - São Paulo, Ed 34 Ltda.

Oliveira, M. O. M. (2011) Práticas Educativas e Narrativas (Auto) Biográficas em Ambientes Virtuais de Aprendizagem. Teias (Rio de Janeiro. Impresso), v. 12, p.

Rodriguez Illera, J. L. (2007) Conferência: como as comunidades virtuais de prática e de aprendizagem podem transformar a nossa concepção de educação. Sísifo. Revista de Ciências da Educação, Lisboa, n. 3, p. 117-124. Disponível em:

https://www.researchgate.net/publication/28175881_Como_as_Comunidades_virtuais_de_prat ica_e_de_aprendizagem_podem_transformar_a_nossa_concepcao_de_educacao.

Silva, A. (2008) Aprendizagem e comunidades de prática. BOCC-Biblioteca On-Line de Ciências da Comunicação: ISSN, p. 1646-3137. Disponível em [http://www.bocc.ubi.pt/pag/silva-adelina-aprendizagem-e-comunidade.pdf].

Thiollent, M. (2009) Pesquisa-Ação nas Organizações. 2.ed. Atlas.

Weinberger, D. (2003), Why Open Spectrum Matters. The end of the broadcast nation. In: http://www.evident.com.

Wenger, È. (1998) Communities of practice. Learning, meaning and identity. Cambridge: Cambridge University Press.

\section{Notas}

${ }^{1}$ Colégio Estadual Governador Luiz Viana Filho. eduardobrito100@hotmail.com 